NOTE

\title{
Packaging of mycosporine-like amino acids in dinoflagellates
}

\author{
Isabelle Laurion ${ }^{1,2, *}$, Frédérick Blouin ${ }^{1,3}$, Suzanne Roy ${ }^{1}$ \\ ${ }^{1}$ Institut des Sciences de la Mer, Université du Québec à Rimouski, 310 Allée des Ursulines, Rimouski, \\ Québec G5L 3A1, Canada \\ ${ }^{2}$ Present address: Institut national de la recherche scientifique, Centre Eau, Terre et Environnement, 2800 rue Einstein, \\ CP 7500, Ste-Foy, Québec G1V 4C7, Canada \\ ${ }^{3}$ Present address: Centre de Recherche sur les Biotechnologies Marines, 265 2ième Rue Est, Rimouski, \\ Québec G5L 9H3, Canada
}

\begin{abstract}
Synthesis of mycosporine-like amino acids (MAAs) can significantly protect phytoplankton cells against damaging ultraviolet (UV) radiation, depending on the concentration, type and cellular distribution of these UV sunscreens. We addressed the hypothesis that MAAs are concentrated around UV-sensitive organelles for improved efficiency, thereby increasing their 'package effect'. This was investigated for 2 species of MAA-producing dinoflagellates, with comparative analyses of a MAA-free diatom. Spectral absorbance of dinoflagellates suspended in their growth medium was relatively small throughout the MAA-absorbing region despite high concentrations of these compounds (determined by HPLC), suggesting that MAAs are highly packaged in intact cells. The measured in vivo absorbance of suspended and filtered phytoplankton cells revealed an extracellular release of water-soluble MAAs during freezing. The release of MAAs upon thawing enabled the calculation of an MAA packaging index based on the comparison between absorption characteristics before (MAAs inside cells in suspension) and after freezing (MAAs released from cells on thawed filters). Additionally, MAA packaging was evaluated from the reconstruction of absorption spectra from the individual MAA concentration. Consistent with our hypothesis, the results showed that UV absorption was up to $80 \%$ lower in the intact cells relative to the MAAs dissolved in solution. These results imply a high degree of MAA packaging in these dinoflagellates, that may increase the protection efficiency for specific cellular targets.
\end{abstract}

KEY WORDS: Package effect · Photoprotection · MAAs - UV-absorbing compounds · Bio-optics · Alexandrium tamarense

\section{INTRODUCTION}

Light absorption by phytoplankton cells is a key process in photosynthesis. In vivo light absorption is highly variable, being affected mostly by photoacclimation (Stramski \& Morel 1990), nutrient status (Sosik \& Mitchell 1995) and cell size (Ohi et al. 2002). UV radiation is also absorbed by phytoplankton and can cause damage to several metabolic pathways (Vincent \& Neale 2000). Cells possess protective mechanisms against UV radiation (Roy 2000), which influence their specific absorption in this waveband. For instance, the accumulation of mycosporine-like amino acids (MAAs) can affect the sensitivity of microalgae to UV radiation (Garcia-Pichel \& Castenholz 1993, Neale et al. 1998). Hence, measurement of cell absorption in the UV range is a factor of interest in photobiology, a field of increasing importance in view of the decline in the stratospheric ozone levels and the climate-induced changes in water UV transparency (Williamson et al. 1996). 
Pigment packaging has a major influence on the light harvesting efficiency of algal cells (Kirk 1994 and references therein). The absorption efficiency of phytoplankton is a non-linear function of pigment concentration, thylakoid arrangement and cell size (Berner et al. 1989, Nelson et al. 1993). A similar packaging effect for UV sunscreens could be of importance to MAAproducing phytoplankton. For UV sunscreens however, packaging can be viewed as effectiveness, since with equal investments, a large organism would benefit more than a small one. The bio-optical model developed by Garcia-Pichel (1994) indicates that MAAs should only be marginally effective at reducing UV radiation due to the short pathlength characteristic of relatively small phytoplankton cells (assuming a homogeneous cytoplasmic distribution of MAAs). However, the localization of MAAs around UV-sensitive organelles (packaged MAAs) might increase their efficiency, although this has not yet been assessed. MAA packaging has been suggested previously for the colonial prymnesiophyte Phaeocystis antarctica (Davidson \& Marchant 1994, Moisan \& Mitchell 2001). However, MAA concentrations observed in colonial prymnesiophytes appeared too high to be contained intracellularly, suggesting their association with the extracellular colonial matrix (Marchant et al. 1991, Riegger \& Robinson 1997).

In the present study, we addressed the hypothesis that MAAs are packaged, likely around UV-sensitive organelles, in 2 MAA-rich dinoflagellate species. Two approaches were taken to test this: (1) by comparing the in vivo UV absorption of suspended dinoflagellate cells with that of filtered and frozen cells (causing a freezing-related release of MAAs). (2) by reconstructing the in vivo UV absorption from the concentration of individual MAAs, as measured by HPLC, following the approach described for pigments in Bidigare et al. (1990). This reconstruction should reproduce the in vivo UV absorption of suspended cells only if no packaging is present (Nelson et al. 1993).

\section{MATERIALS AND METHODS}

Mono-specific cultures included 3 dinoflagellates, 2 strains of Alexandrium tamarense (ProvasoliGuillard National Center for Culture of Marine Phytoplankton CCMP116, isolated from Ría de Vigo, Spain, and CCMP1771, isolated from the Tamar Estuary, England; hereafter Ate and At), 1 of Heterocapsa triquetra (CCMP449; Ht), and 1 diatom, Thalassiosira pseudonana (CCMP1335; Tp). Cells were grown under ca. $300 \mu \mathrm{mol}$ photons $\mathrm{m}^{-2} \mathrm{~s}^{-1}$ of incident PAR enriched with UVA radiation (identified with ' + ') and under reduced irradiance (ca. $200 \mu \mathrm{mol}$ photons $\mathrm{m}^{-2} \mathrm{~s}^{-1}$ of incident PAR) without supplemented UVA (identified with '-'), to generate different concentrations of MAAs (see Laurion et al. 2003 for details).

For chl $a$ and MAA measurements, 8 to $25 \mathrm{ml}$ of the cultures were filtered onto glass fiber filters and kept at $-80^{\circ} \mathrm{C}$ until subsequent extraction. Chl a concentration was measured by HPLC following the method of Zapata et al. (2000; mobile phase B1). MAAs were extracted in $25 \%$ aqueous methanol (vol:vol) following a 2-step procedure, and separated by reverse-phase isocratic HPLC (Shick et al. 1999). Details are given in Laurion et al. (2003). A $20 \mathrm{ml}$ subsample was fixed with acidified Lugol's solution and cells were counted under an inverted microscope.

The absorption spectra of phytoplankton suspensions were obtained using a Perkin-Elmer Lambda 2 spectrophotometer equipped with an integrating sphere (Labsphere RSA-PE-20). Absorbance was measured between 280 and $850 \mathrm{~nm}\left(\mathrm{OD}_{\mathrm{s}}\right)$. The absorbance of the dissolved organic matter naturally released in the media during growth $\left(\mathrm{OD}_{\text {fil }}\right)$ was also measured (except for $\mathrm{Tp}$; this was checked a few weeks later and the absorbance by DOM remained low for this strain). For this, cells were removed by low-pressure filtration. For measurements of particle absorbance from filter pads, $1.86 \mathrm{ml}$ aliquots were filtered onto glass fibre filters. One set of duplicate filters was frozen immediately in liquid nitrogen and stored at $-80^{\circ} \mathrm{C}$ for $2 \mathrm{~d}\left(\mathrm{OD}_{\mathrm{f} \text { frozen }}\right)$. $\mathrm{A}$ second set of filters was stored frozen as above, but upon thawing the filters were rinsed with $5 \mathrm{ml}$ filtered sea water $(0.2 \mu \mathrm{m})$ before they were scanned $\left(\mathrm{OD}_{\mathrm{f} \text { frozen }}\right.$ rinsed). This step accounted for the water-soluble material that might have exuded from the algal cells or been released upon cell breakage. The filtrate of this rinsing step was kept for further analysis ( $\mathrm{OD}_{\text {rinsing }}$ ). Details on baseline and blank corrections, and null point adjustment are given in Laurion et al. (2003).

\section{RESULTS}

Both dinoflagellate species had high concentrations of MAAs, ranging from 5.6 to $14.5 \mu \mathrm{g}$ MAAs $\mu \mathrm{g} \mathrm{chl} a^{-1}$ (35.0 to 329.5 pg MAAs per cell) depending on species and growth conditions (Table 1). This table also presents concentrations in MAAs per cell volume (assuming ellipsoidal cells). These concentrations fall in the range of values found in cultured and natural marine dinoflagellates (e.g. Neale et al. 1998, Whitehead \& Vernet 2000; see Laurion et al. 2002 for a comparison table). Carreto et al. (2001) found a lower MA concentration in cultures of $A$. tamarense (6.18 pg cell ${ }^{-1}$ ), likely related to the low growth irradiance used (65 $\mu \mathrm{mol}$ photons $\mathrm{m}^{-2} \mathrm{~s}^{-1}$ ). A total of 7 MAAs were identified, with 1 additional abundant MAA absorbing at $333 \mathrm{~nm}$ (M333; Table 1). Unidentified MAAs (excluding M333) re- 


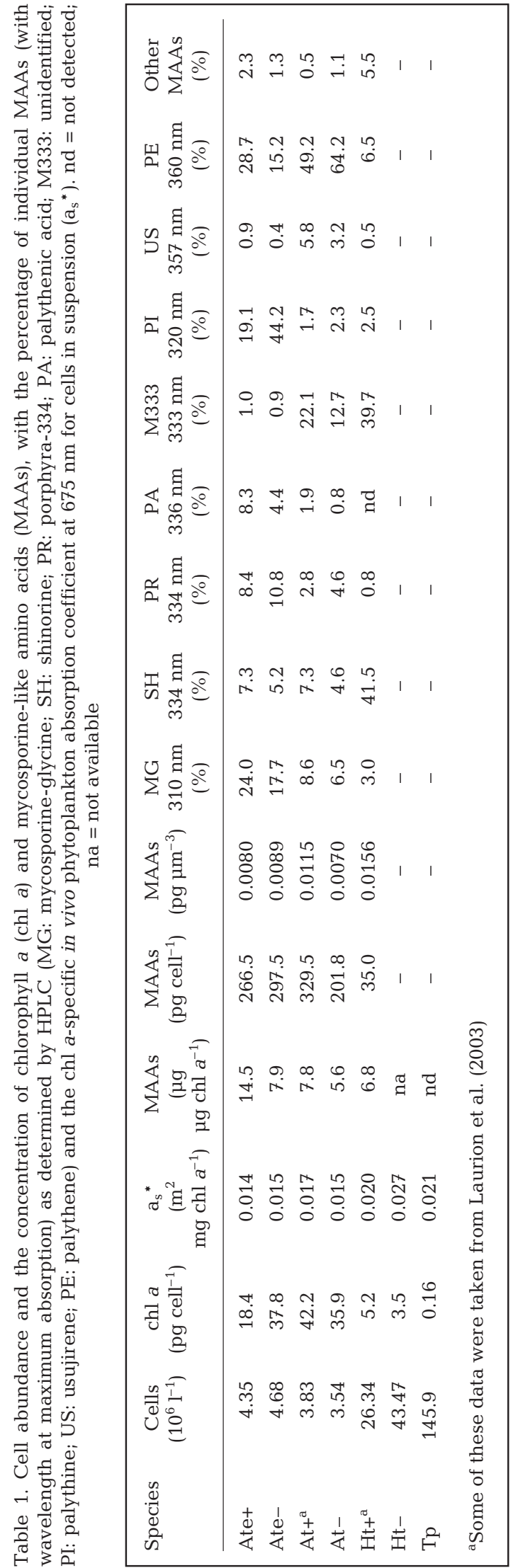

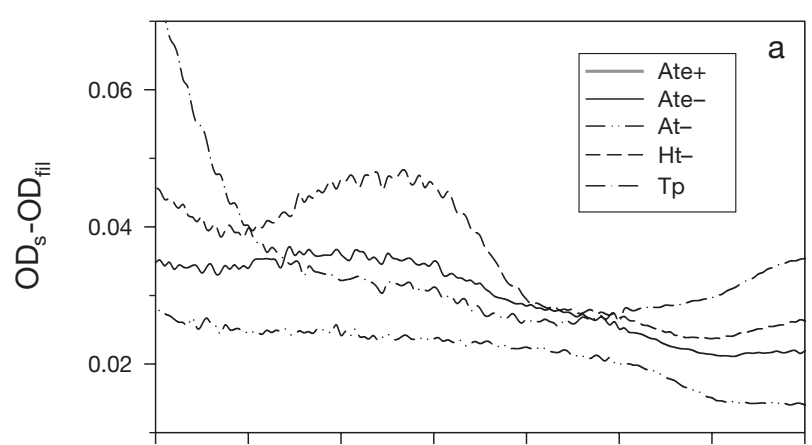

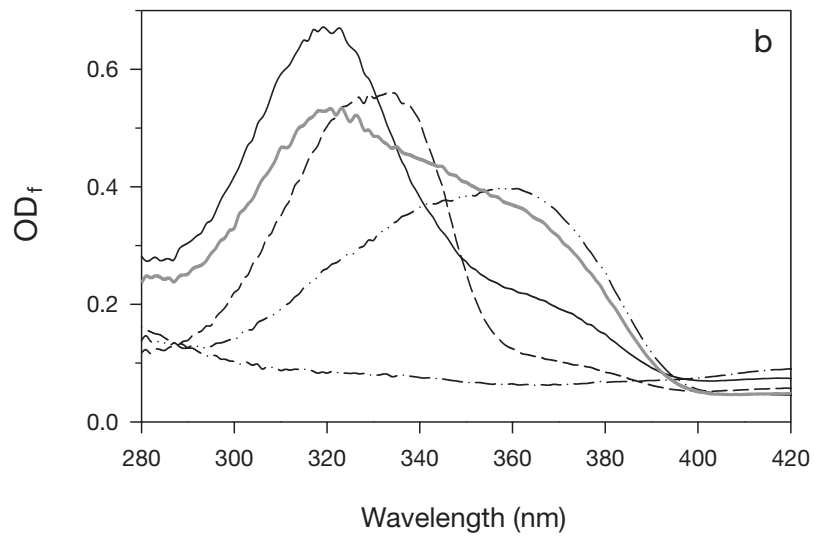

Fig. 1. Absorbance spectra in the UV waveband of (a) suspended cells $\left(\mathrm{OD}_{\mathrm{s}}-\mathrm{OD}_{\text {fil }}\right)$ and (b) frozen filters for Ate+, Ate-, At-, Ht- and Tp $\left(\mathrm{OD}_{\mathrm{f}}\right.$ frozen $)$. OD $\mathrm{D}_{\text {fil }}$ was subtracted from $\mathrm{OD}_{\mathrm{s}}$ except for $\mathrm{Tp}$ (explaining the increase of OD toward lower wavelengths)

mained below $6 \%$ of total MAAs eluted. No MAAs appeared in the chromatograms of Tp.

The in vivo absorbance spectra of suspended cells are presented in Fig. 1a (spectra were selected to optimize the presentation). Despite high MAA concentrations, the UV absorbance of suspended cells of the dinoflagellates is relatively flat compared to scans of filtered cells. These spectra were corrected for the absorbance of dissolved compounds in the culture media. Cultures of Ht had considerable amounts of dissolved organic compounds, the shape of the spectra indicating a strong contribution of dissolved MAAs (see Laurion et al. 2003, their Figs. 3 \& 4).

The MAA composition (Table 1) corresponded closely to the shape of the spectral absorbance of filtered cells (Fig. 1b). The diverse assemblage of MAAs in Ate gave a wide peak in the in vivo absorbance spectrum, whilst the dominance of M333 and palythene in At shifted the UV absorbance peak toward higher wavelengths. The dominance of 2 MAAs absorbing at roughly the same wavelength in Ht gave a narrower absorbance peak. Such large UV absorbance peaks for filtered cells have been reported in some other studies (Neale et al. 1998, Sosik 1999) and is 
related to the effect of handling (at least for these dinoflagellates; Laurion et al. 2003). These results suggest that a gradual release of MAAs started immediately after or during filtration, while freezing greatly increased this release. When thawed filters were rinsed with filtered seawater prior to scanning, this large UV peak found with frozen filters decreased considerably (more than $98 \%$ of the MAA peak disappeared for Ate and At and more than $90 \%$ for $\mathrm{Ht}$ ) and appeared in the rinsing water.

The freezing-related release of MAAs allowed us to calculate an index of MAA packaging $\left(\mathrm{pi}_{1}=1-\right.$ $\left[O D_{\text {s-fil }} \times \beta / O D_{f}\right.$ frozen $]$ ), assuming that MAAs were unpackaged in thawed cells on filters. The absorbance of suspended cells $\left(\mathrm{OD}_{\mathrm{s}}\right)$ was corrected for the absorbance of the medium $\left(\mathrm{OD}_{\text {fil }}\right)$ and for pathlength amplification ( $\beta$ ) caused by multiple scattering of light through the filter (Kiefer \& SooHoo 1982). $\beta$ values were obtained empirically from the ratio of filtered to suspended absorption averaged over the visible waveband (the 'true' pathlength amplification) i.e. where there was no artifact caused by the presence of MAAs. Highly packaged MAAs should cause low values of $\mathrm{OD}_{\text {s-fil }}$ (corrected for $\beta$ ) compared to $\mathrm{OD}_{\mathrm{f} \text { frozen. }}$. The $\mathrm{pi}_{1}$ values calculated varied between 0 and 0.94 , depending on species and growth light conditions, and were maximal at the same wavelengths as for the absorbance spectra. Values of $\mathrm{pi}_{1}$ averaged over 280 to $380 \mathrm{~nm}$ are given in Table 2 . This index of MAA packaging can be considered a minimum in the case of $\mathrm{Ht}$, since an unknown fraction of MAAs was not released out of thawed cells.

Fig. 2 shows the reconstruction of spectral absorption in Ate cultures grown with and without additional UVA, following the approach of Bidigare et al.

Table 2. Averaged packaging index (pi) of MAAs calculated over 280 to $380 \mathrm{~nm}: \mathrm{pi}_{1}=1-\left(\mathrm{OD}_{\mathrm{s} \text {-fil }} \times \beta / \mathrm{OD}_{\mathrm{f} \text { frozen }}\right), \mathrm{pi}_{2}=1-$ $\left(\mathrm{OD}_{\text {s-fil }} / \mathrm{OD}_{\text {sum+det }}\right)$. The $\beta$ values used are the averages obtained over the visible waveband, i.e. where there is no artifact caused by the presence of MAAs. $\mathrm{pi}_{2}$ is calculated from spectral reconstruction based on the concentration and spectral characteristics of the various MAAs present; no $\mathrm{pi}_{2}$ values are available for $\mathrm{Ht}-$ and $\mathrm{Tp}$ because there are no MAAs available or present (cf. Table 1)

\begin{tabular}{|lcc|}
\hline Species & $\mathrm{pi}_{1}$ & $\mathrm{pi}_{2}$ \\
\hline Ate+ & 0.88 & 0.80 \\
Ate- & 0.65 & 0.56 \\
At+ & 0.77 & 0.62 \\
At- & 0.69 & 0.51 \\
Ht+ & 0.62 & 0.41 \\
Ht- & 0.63 & - \\
Tp & 0.02 & - \\
\hline
\end{tabular}
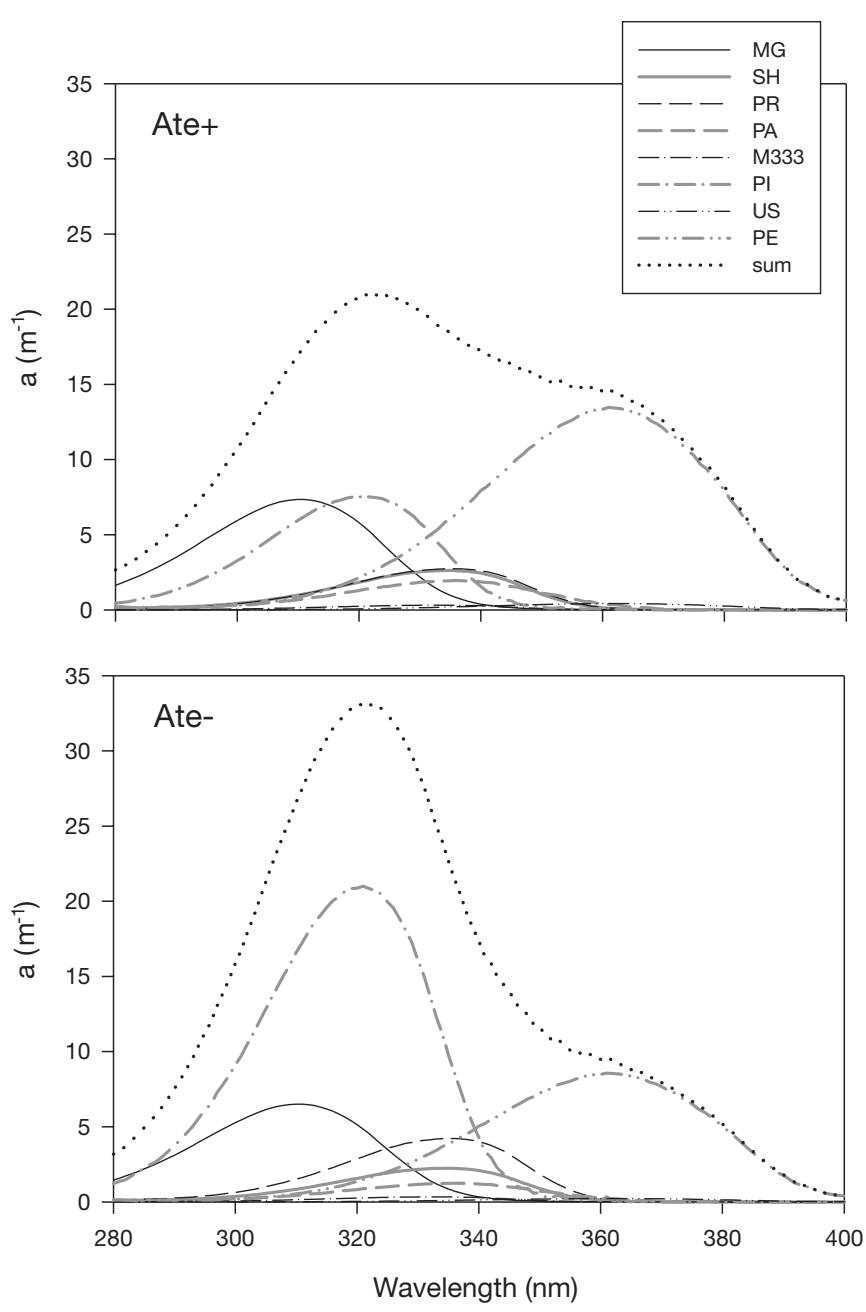

Fig. 2. Reconstruction of spectral absorption from individual MAA concentrations (HPLC) in Ate cultures grown with (Ate+) and without (Ate-) additional UVA

(1990) for pigments (unidentified MAAs were not included). The difference between light treatments is particularly striking at $360 \mathrm{~nm}$, where the abundance of PE affects the shape of the spectra. The summed MAA absorbance, $\mathrm{OD}_{\text {sum, }}$ was highly correlated with values obtained from the frozen filter rinsing water, $\mathrm{OD}_{\text {rinsing }}$ (Pearson Product Moment correlations for the dinoflagellates; $\mathrm{r}>0.97$ and $\mathrm{p}<0.0001$; absorption coefficients for Ate+ shown in Fig. 3). OD sum was added to a spectrum of detrital particles $\left(\mathrm{OD}_{\text {deti }}\right.$ estimated by fitting an exponential curve under the suspended cell spectra of each culture) and was then compared to the absorbance of suspended cells to estimate an MAA packaging index $\mathrm{pi}_{2}=1-\left(\mathrm{OD}_{\mathrm{s} \text {-fil }} /\right.$ $\mathrm{OD}_{\text {sum+det }}$ ). Values of $\mathrm{pi}_{2}$ are lower than $\mathrm{pi}_{1}$ (Table 2), but both indexes are highly correlated (Pearson Product Moment correlation, $\mathrm{r}=0.95, \mathrm{p}=0.0136$ ). 


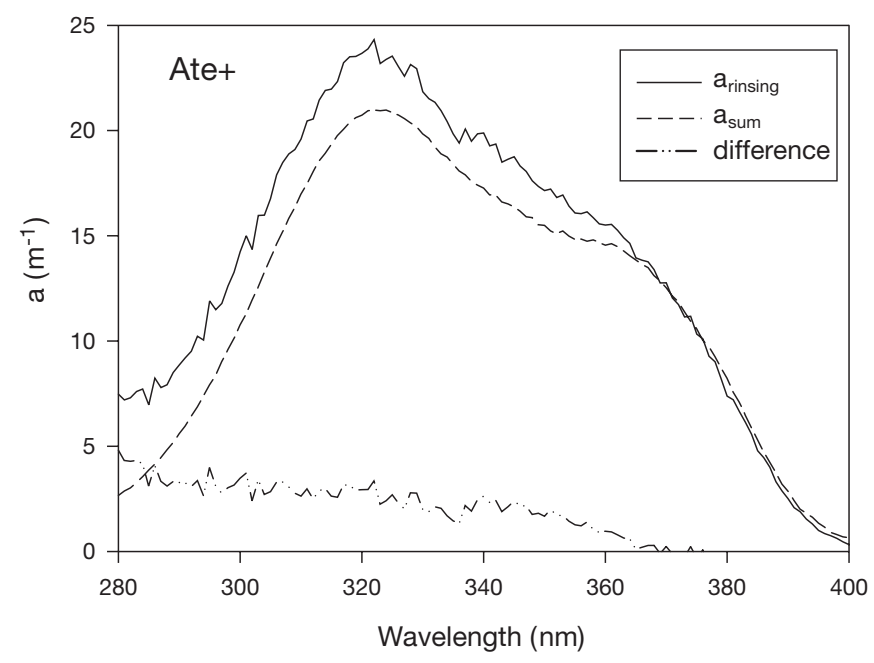

Fig. 3. Comparison between the absorption coefficients of water-soluble material exuded out of cells upon freezing (collected by a rinsing step) and the absorption reconstructed from the MAA concentrations obtained by HPLC for Ate+

\section{DISCUSSION}

The flattening of the absorbance spectra for cells in suspension (Fig. 1) can be explained by the package effect (or internal self-shading) of MAAs. Duysens (1956) demonstrated theoretically that the absorption spectrum of a substance contained in particles appears flattened when compared with the absorption of the same substance (same concentration) in solution. The flattening in the UV waveband likely depends on the shape and size of cells, but also on the composition and internal distribution of the UV absorbing compounds within the cells (as seen for pigments in the visible range; e.g. Sathyendranath et al. 1987). A nonhomogenous distribution of MAAs in the cells, targeted around UV-sensitive organelles for increased protection efficiency, has been suggested by Neale et al. (1998) and could be a major cause of this UV flattening. Even if measured cell absorption of UV radiation is reduced when MAAs are packaged, the protection efficiency of specific targets would increase, affecting the estimation of sunscreen photoprotection, i.e. the proportion of damaging photons prevented from reaching sensitive targets. The sunscreen factor developed by Garcia-Pichel (1994) corresponds to the fractional reduction of UV exposure to a centrally located cellular target when MAAs are synthesized as a response of light conditions (Riegger \& Robinson 1997, Bracher \& Wienke 2000). However, this factor cannot be calculated here, since the dinoflagellate cultures grown under both light treatments contained significant MAA concentrations (MAA-free back- ground efficiency factor for internal self-shading cannot be calculated).

Both methods used in this study to evaluate MAA packaging gave essentially the same results, except that $\mathrm{pi}_{1}$ was slightly higher than $\mathrm{pi}_{2} \cdot \mathrm{pi}_{1}$ could possibly be overestimated if $\beta$ values were underestimated or other optical effects associated with the filter pad technique were occurring. Spectral reconstruction of dissolved absorption from individual MAA absorbance spectra and concentration (Bidigare et al. 1990) appeared to be accurate, since when converted into comparable units, the reconstructed absorption was only slightly lower than the absorption obtained from the rinsing water (i.e. what was released from cells upon thawing; Fig. 3).

Both strains of Alexandrium tamarense grown under enhanced UVA irradiance ('+' cultures) had a higher index of MAA packaging compared to cultures grown without additional UVA ('-' cultures). This was not the case for $\mathrm{Ht}$ (comparison of $\mathrm{pi}_{1}$ only), but the packaging index for this species was biased by the incomplete release of MAAs during freezing (full extraction of MAAs for HPLC analysis required sonication for $\mathrm{Ht}$, but not for At, possibly because they have more resistant membranes). The highest index of packaging was found in Ate+ (average $\mathrm{pi}_{1}=0.80$ ), with an $80 \%$ decrease in UV absorption in cells relative to solution. This culture had indeed the highest concentration of MAAs relative to chl a (Table 1). It is also interesting to note that these 2 strains of the same species, A. tamarense, responded slightly differently to the same light treatment, likely indicating differences in photoadaptation and genetic characteristics (Ate was isolated from Spain, while At came from England). The lower packaging index found in $\mathrm{Ht}$ is consistent with the smaller cell size of this dinoflagellate (diameter of ca. $18 \mu \mathrm{m}$, compared to ca. $38 \mu \mathrm{m}$ for A. tamarense). Outdoor cultures of these dinoflagellates increased their production of MAAs under enhanced UVB doses as compared to natural sunlight conditions, Ate being more successful than At and $\mathrm{Ht}$, since it was able to maintain similar growth rates under both UVB treatments (Laurion \& Roy unpubl.).

Interestingly, higher pi values corresponded to higher concentrations of MAAs normalized to chl $a_{\text {, }}$ but not always when normalized to cell number or cell volume (Tables $1 \& 2$ ), suggesting that MAAs are associated with chloroplasts. It is worthwhile noting that packaging of pigments also occurs in the MAA-rich Alexandrium tamarense cells, as seen from the lower value of the chl a-specific absorption coefficient for cells in suspension $\left(\mathrm{a}_{\mathrm{s}}{ }^{*}\right.$ at $675 \mathrm{~nm}$; Table 1) compared to the specific absorption coefficient of $\mathrm{chl} a$ in solution (equal to $0.0207 \mathrm{~m}^{2} \mathrm{mg} \mathrm{chl} \mathrm{a}^{-1}$ at $675 \mathrm{~nm}$; Bricaud et al. 1983, Nelson et al. 1993). MAAs may associate somehow with the pigment packets inside chloroplasts. 
Considering the high cost of MAA synthesis (Raven 1991, Shick \& Dunlap 2002) and their restricted sunscreen efficiency in small cells (2 to $20 \mu \mathrm{m}$; GarciaPichel 1994), packaging of MAAs around sensitive sites (e.g. nucleus, chloroplasts) may increase the efficiency of photoprotection for small phytoplankton cells, as compared to a homogeneous cytoplasmic distribution of these sunscreens (such as found in cyanobacteria; Garcia-Pichel \& Castenholz 1993). Since MAAs are formed via the shikimate pathway (Shick et al. 1999), they are likely produced in the chloroplasts, which may be connected to the nucleus (Falkowski \& Raven 1997). A package index of 0.8 would correspond to MAAs concentrated in $1 / 5$ of the total cell volume (assuming that Beer's law applies). This seems possible if MAAs are enclosed within the chloroplasts, since chloroplasts often represent a fairly large fraction of the cell volume. One may question the physiological limit of such high concentrations of MAAs (e.g. $330 \mathrm{pg}$ in one cell of At corresponds to an average cellular concentration of $40 \mathrm{mmol} \mathrm{l}^{-1}$ ) if they were restricted to a small fraction of the cell volume. For example, the MAAs restricted to $1 / 5$ of the total volume would give a concentration of $0.2 \mathrm{~mol} \mathrm{l}^{-1}$, which corresponds to the estimated maximal content of UV sunscreens considering the osmotic pressure (Garcia-Pichel 1994). The above considerations hold for freely diffusing MAAs, which may not be the case for all MAAs, as some do not seem to be readily extractable (see Tartarotti \& Sommaruga 2002). The above issues need further investigation to fully understand the cellular distribution of MAAs in different species and to assess their photoprotective efficiency.

Acknowledgements. We thank D. Karentz for providing secondary standards of MAAs, K. Whitehead for LC-MS analyses that were performed to confirm the identification of most MAAs, M. Shick for fruitful discussions, D. Mueller, W. Vincent, A. Morel, A. Weidemann and an anonymous reviewer for insightful comments and careful reviews and G. Ouellet for microscopic counts. Funds from the Natural Sciences and Engineering Research Council of Canada (I.L. and S.R.) supported this research.

\section{LITERATURE CITED}

Berner T, Dubinsky Z, Wyman K, Falkowski PG (1989) Photoadaptation and the 'package' effect in Dunaliella tertiolecta (Chlorophyceae). J Phycol 25:70-78

Bidigare RR, Ondrusek ME, Morrow JH, Kiefer DA (1990) In vivo absorption properties of algal pigments. In: Spinrad RW (ed) Ocean Optics X, Proc SPIE (Photo-Opt Instrum Eng) 1302:290-302

Bracher AU, Wiencke C (2000) Simulation of the effects of naturally enhanced UV radiation on photosynthesis of Antarctic phytoplankton. Mar Ecol Prog Ser 196:127-141

Bricaud A, Morel A, Prieur L (1983) Optical efficiency factors of some phytoplankters. Limnol Oceanogr 35: $562-582$
Carreto JI, Carignan MO, Montoya NG (2001) Comparative studies on mycosporine-like amino acids, paralytic shellfish toxins and pigment profiles of the toxic dinoflagellates Alexandrium tamarense, A. catenella and A. minutum. Mar Ecol Prog Ser 223:49-60

Davidson AT, Marchant HJ (1994) The impact of ultraviolet radiation on Phaeocystis and selected species of Antarctic marine diatoms. In: Weiler CS, Penhale PA (eds) Ultraviolet radiation and biological research in Antarctica, Antarctic Research Series 62. American Geophysical Union, Washington, DC, p 187-205

Duysens LNM (1956) The flattening of the absorption spectrum of suspensions as compared to that of solutions. Biochim Biophys Acta 19:1-12

Falkowski PG, Raven JA (1997) Aquatic photosynthesis. Blackwell Science, Malden, MA

Garcia-Pichel F (1994) A model for internal self-shading in planktonic organisms and its application for the usefulness of ultraviolet sunscreens. Limnol Oceanogr 39: 1704-1717

Garcia-Pichel F, Castenholz RW (1993) Occurrence of UVabsorbing, mycosporine-like compounds among cyanobacterial isolates and an estimate of their screening capacity. Appl Environ Microbiol 59:163-169

Kiefer DA, Soohoo JB (1982) Spectral absorption by marine particles of coastal waters of Baja California. Limnol Oceanogr 27:492-499

Kirk JTO (1994) Light and photosynthesis in aquatic ecosystems, 2nd edn. Cambridge University Press, Cambridge

Laurion I, Lami A, Sommaruga R (2002) Distribution of mycosporine-like amino acids and photoprotective carotenoids among freshwater phytoplankton assemblages. Aquat Microb Ecol 26:283-294

Laurion I, Blouin F, Roy S (2003) The quantitative filter technique for measuring phytoplankton absorption: interference by MAAs in the UV waveband. Limnol Oceanogr $1: 1-9$

Marchant HJ, Davidson AT, Kelly GJ (1991) UV-B protecting compounds in the marine alga Phaeocystis pouchetii from Antarctica. Mar Biol 109:391-395

Moisan TA, Mitchell BG (2001) UV absorption by mycosporine-like amino acids in Phaeocystis antarctica Karsten induced by photosynthetically available radiation. Mar Biol 138:217-227

Neale PJ, Banaszak AT, Jarriel CR (1998) Ultraviolet sunscreens in Gymnodinium sanguineum (Dinophyceae): mycosporine-like amino acids protect against inhibition of photosynthesis. J Phycol 34:928-938

Nelson NB, Prézelin BB, Bidigare RR (1993) Phytoplankton absorption and the package effect in California coastal waters. Mar Ecol Prog Ser 94:217-227

Ohi N, Ishiwata Y, Taguchi S (2002) Diel patterns in light absorption and absorption efficiency factors of Isochrysis galbana (Prymnesiophyceae). J Phycol 38:730-737

Raven JA (1991) Responses of aquatic photosynthetic organisms to increased solar UVB. J Photochem Photobiol B9: $239-244$

Riegger L, Robinson D (1997) Photoinduction of UV-absorbing compounds in Antarctic diatoms and Phaeocystis antarctica. Mar Ecol Prog Ser 160:13-25

Roy S (2000) Strategies for the minimisation of UV-induced damage. In: de Mora S, Demers S, Vernet M (eds) The effects of UV radiation in the marine environment. Cambridge University Press, Cambridge, p 177-205

Sathyendranath S, Lazzara L, Prieur L (1987) Variations in the spectral values of specific absorption of phytoplankton. Limnol Oceanogr 32:403-415 
Shick JM, Dunlap WC (2002) Mycosporine-like amino acids and related gadusols: biosynthesis, accumulation, and UV-protective functions in aquatic organisms. Annu Rev Physiol 64:223-262

Shick, JM, Romaine-Lioud S, Ferrier-Pagès C, Gattuso JP (1999) Ultraviolet-B radiation stimulates shikimate pathwaydependent accumulation of mycosporine-like amino acids in the coral Stylophora pistillata despite decreases in its population of symbiotic dinoflagellates. Limnol Oceanogr 44: $1667-1682$

Sosik HM (1999) Storage of marine particulate samples for light-absorption measurements. Limnol Oceanogr 44: $1139-1141$

Sosik HM, Mitchell BG (1995) Light absorption by phytoplankton, photosynthetic pigments and detritus in the California Current System. Deep-Sea Res 42:1717-1748

Stramski D, Morel A (1990) Optical properties of photosynthetic picoplankton in different physiological states as affected by growth irradiance. Deep-Sea Res 37:245-266

Tartarotti B, Sommaruga R (2002) The effect of different

Editorial responsibility: Otto Kinne (Editor), Oldendorf/Luhe, Germany methanol concentrations and temperatures on the extraction of mycosporine-like amino acids (MAAs) in algae and zooplankton. Arch Hydrobiol 154:691-703

Vincent WF, Neale PJ (2000) Mechanisms of UV damage to aquatic organisms. In: de Mora S, Demers S, Vernet M (eds) The effects of UV radiation in the marine environment. Cambridge University Press, Cambridge, p 149-176

Whitehead K, Vernet M (2000) Influence of mycosporine-like amino acids (MAAs) on UV absorption by particulate and dissolved organic matter in La Jolla Bay. Limnol Oceanogr 45:1788-1796

Williamson CE, Stemberger RS, Morris DP, Frost TM, Paulsen SG (1996) Ultraviolet radiation in North American lakes: attenuation estimates from DOC measurements and implications for plankton communities. Limnol Oceanogr 41: 1024-1034

Zapata M, Rodriguez F, Garrido JL (2000) Separation of chlorophylls and carotenoids from marine phytoplankton: a new HPLC method using reverse phase C8 column and pyridinecontaining mobile phase. Mar Ecol Prog Ser 195:29-45

Submitted: January 19, 2004; Accepted: July 4, 2004

Proofs received from author(s): September 6, 2004 